\title{
Hospital selection in emergency medical service systems: A literature review*
}

\section{Selección de hospital en los sistemas de servicios médicos de emergencia: una revisión de literatura}

\section{Seleção de hospitais em sistemas de serviços médicos de emergência: uma revisão da literatura}

Received: October 16, 2019. Accepted: August 17, 2020.

Published: June 30, 2021.

DOI: https://doi.org/10.11144/Javeriana.rgps20.hsem

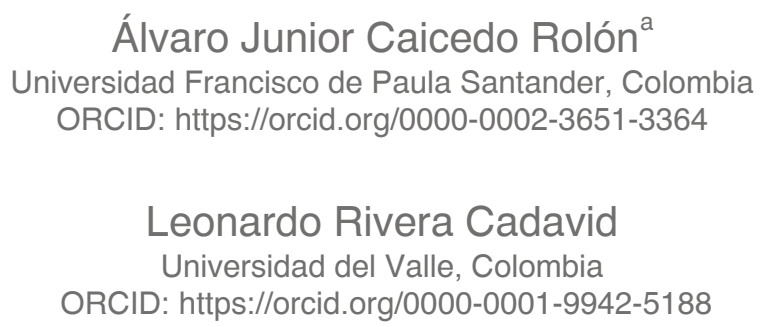

Cited as: Caicedo AJ, Rivera L. Hospital selection in emergency medical service systems: A literature review. Rev Gerenc Polit Salud. 2021;20. https://doi.org/10.11144/Javeriana.rgps20.hsem

\footnotetext{
* Review article.

a Corresponding author. E-mail: alvarojuniorcr@ufps.edu.co
} 


\section{Abstract}

Emergency medical service (EMS) systems play a fundamental role in society by providing a vital service in initial emergency care. The purpose of this research is to present the first literature review of hospital selection operational decision within the context of the EMS system. The main findings were the following: The hospital selection problem is integrated with the location, dispatch, routing, and size of the ambulance fleet. The main selection criteria were closeness, hospital care capacities and the shortest queue or greatest number of free beds. The most used performance measures were the shortest transport and waiting time. Solution techniques include discrete event simulation, queuing models, mixed linear integer programming, and CPLEX and Arena software. The application of metaheuristics is scarce; mobile applications and Internet information systems have been implemented for real-time decision making. It is recommended that the design of hospital selection methods be implemented as well as the technological developments, considering the participation of the actors of the EMS system.

Keywords: Ambulances, emergencies, health services administration, information technology.

\section{Resumen}

Los sistemas de servicios médicos de emergencia (SME) desempeñan una función fundamental en la sociedad al prestar un servicio vital en la atención inicial de urgencias. La investigación presenta la primera revisión de la literatura que estudia el problema de selección de hospital en los sistemas de SME. Los principales hallazgos fueron: la integración de la decisión de selección del hospital con la localización y el número de ambulancias, el despacho o el enrutamiento de las ambulancias. Los principales criterios de selección fueron la cercanía, las capacidades de atención del hospital y la fila más corta o mayor número de camas libres. Las medidas de desempeño más usadas fueron el menor tiempo de traslado y de espera. Las metodologías cuantitativas más aplicadas fueron la simulación de eventos discretos, los modelos de colas y la programación lineal entera mixta y los software CPLEX y Arena. La aplicación de metaheurísticas es escasa, se han implementado aplicaciones móviles y sistemas de información por internet para la selección del hospital en tiempo real. Se recomienda implementar el diseño de los métodos de selección de hospitales y los desarrollos tecnológicos, considerando la participación de los actores del sistema SME.

Palabras clave: Ambulancias, urgencias médicas, administración de los servicios de salud, tecnología de la información.

\section{Resumo}

Os sistemas de atendimento médico de emergência (AME) desempenham um papel fundamental na sociedade por fornecer um serviço vital no atendimento inicial de emergência. O objetivo desta pesquisa é apresentar a primeira revisão da literatura sobre a decisão operacional de seleção de hospitais no contexto dos sistemas de AME. As principais conclusões foram as seguintes: o problema de seleção do hospital está integrado à localização, envio, rota e tamanho da frota de ambulâncias. Os principais critérios de seleção foram proximidade, capacidade de atendimento hospitalar e menor fila ou maior número de leitos livres. As medidas de desempenho mais utilizadas foram o menor tempo de transporte e de espera. As técnicas de solução incluem simulação de eventos discretos, modelos de enfileiramento, programação inteira linear mista e software CPLEX e Arena. A aplicação de metaheurísticas é escassa; aplicativos móveis e sistemas de informação da Internet foram implementados para a tomada de decisões em tempo real. Recomenda-se que seja implementado o desenho de métodos de seleção de hospitais e também os desenvolvimentos tecnológicos, considerando a participação dos atores do sistema AME.

Palavras-chave: Ambulâncias, emergências, administração de serviços de saúde, tecnologia da informação. 


\section{Introduction}

The emergency medical service (EMS) refers to the ambulance service and the EMS system is an integrated general model of a public safety and health care system that includes the mechanisms for notifying medical emergencies, the provision of pre-hospital and emergency services, basic and medicalized forms of transportation, hospital care, the work of emergency regulatory centers, among others. The purpose of EMS is to respond in a timely and efficient manner to victims of diseases and accidents that require emergency medical attention (1-3). They are classified in the Anglo-American model and European Model. In the Anglo-American model, initial care is provided by paramedics who transport patients to the hospital system. The European model (French, German and Spanish) is medicalized and facilitate in-situ hospital medical services (takes the hospital to the patient) $(4,5)$.

The importance and sensitivity of the decision making in the EMS have been recognized by operations research scientists, EMS planners and health professionals who studied problems in EMS system management (6). These problems can be classified into strategic, tactical and operational according to the decision-making levels. Strategic decisions are related to the location of ambulance bases and medical care centers, number and type of ambulances, and territory division into districts. Tactical problems involve selection and hiring of personnel, programming of the crew and shifts, and assignment of ambulances to types of tasks such as emergencies or transfer requests. Operational decisions are made in real time and are associated to relocation, dispatch, ambulances routing policies, and hospital selection (4,7-9).

EMS systems lack efficient processes for hospital selection decision making that consider criteria and performance measures focused on improving the patient care experience (10-13). The selection of the hospital is one of the least studied problems in the literature (11), so it is recommended that more hospital selection algorithms be proposed (12), as well as new methods to determine the best ambulance and hospitals, for fast and accurate decision making (14). The selection of the appropriate hospital with available capacity is a critical and complex decision in real time that impacts EMS systems efficiency $(12,13,15)$ and affects transfer time (transport time + queuing time), which is a measure of performance related to the welfare and safety of patients. The problem of hospital selection is becoming increasingly important due to the problems of overcrowding in emergency rooms (13).

Below are literature reviews related to the strategic, tactical and operational problems in the EMS system. An extensive literature examination is made of the recent developments in operations research techniques for ambulance dispatch and location problems (7). A revision and analysis of the literature of the EMS system are presented, where the concept of the emergency care route is introduced following current trends in the health system (6). A general perspective of the logistical problems that arise for EMS providers is proposed. Approaches and methods for each strategic, tactical, and operational planning problems are shown (4). A review of the literature on the EMS vehicle relocation problem was carried out, considering policies, solution methods, software and performance measures among others (16). A critical overview of the 
existing literature on simulation models applied in EMS operations is provided, pointing out the problems considered, the modeling assumptions and the results obtained (9).

Many review articles have discussed EMS localization problems (6) and most of the literature related to EMS systems specifically focus on: location, relocation, dispatch and ambulances routing policies as manifested in $(4,8,12,17-20)$. In accordance with the above and with the best knowledge of the authors, there is no evidence of literature review on the selection decision of the hospital, therefore, this research would be a valuable contribution to fill that gap and promote scientific advancement in the study of EMS systems.

The purpose of the research was to present a literature review that addresses the problem of hospital selection in EMS systems. The article presents the following sections: the second presents the methodology used to search for information; the third presents findings including research objectives, hospital selection criteria, performance measures considered, quantitative methodologies, applied software and Information and Communication Technologies (ICT) that have been evaluated or proposed to address the problem of hospital selection in EMS systems; finally, the discussion and conclusions of the research are presented.

\section{Methods}

As a search strategy, publications that fulfilled the following criteria were selected: 1) those that involve the operational decision of hospital selection or assignment patients to hospitals, under emergency conditions, by means of quantitative methods and ICT developments; 2) those that mention hospital selection criteria, within other strategic, tactical, and operational problems, treated as main problems in these studies; and 3) those that they have identified the selection criteria of the hospital, according to the experiences of patients transferred by ambulances. Publications that did not evidence criteria for hospital selection were excluded.

We initially defined the components of the question according to the PICO strategy (Patient or Problem, Intervention, Comparator, Outcome) (21), which were P: Selection of the hospital for ambulance transportation of patients in emergency conditions. I: Quantitative methods, theoretical models, as well as developments in information and communication technologies used to choose the best destination hospital. C: Not applicable. O: Improvement of EMS system performance measures such as reduced transport times, waiting times, mortality rates, workload balance, among others. Subsequently, the descriptors were searched in $\mathrm{MeSH}$, corresponding to the components of the question, with which the following search terms, used in MEDLINE, were constructed: (("Emergency Medical Services/organization and administration"[Mesh]) AND "Models, Theoretical"[Mesh]) AND "Ambulances"[Mesh]; (("Emergency Medical Service Communication Systems"[Mesh]) AND "Models, Theoretical"[Mesh]) AND "Ambulances"[Mesh]; (("Emergency Medical Service Communication Systems"[Mesh]) AND "Geographic Information Systems"[Mesh]) AND "Ambulances"[Mesh]. 
At the same time, the Scopus, Web of Science, Science Direct and Springer databases were consulted using keywords such as ("emergency medical service" OR "emergency medical service system" OR "emergency medical system") AND ("hospital selection" OR "ambulance logistic" OR "emergency department"). Duplicate documents were removed. Also, more publications were identified based on the reference list from the selected documents. The selection was carried out through the review of the title, abstract and the conclusions of the publications. Finally, 49 documents were selected, including journal articles (47.92\%), conference articles (37.5\%), doctoral dissertations $(8.33 \%)$, book chapters $(4.17 \%)$ and technical reports $(2.08 \%$ ). $68.75 \%$ were published after $2010,20.83 \%$ during the first decade of the millennium and $10.42 \%$ in the last century. Of the publications, $37.5 \%$ were published in the USA, 6.25\% in Canada, 33.33\% in Asia, 10.42\% in Europe, and the rest in the Middle East, Africa, Australia and South America.

From the literature review it was possible to obtain the research objectives, the hospital selection criteria and performance measures, the applied quantitative methodologies and tools, and the ICT used and developed. Each of these aspects is presented in tables, which organize the information in order of importance, accompanied by a description of each of the publications, grouped by hospital selection criteria individually or integrated.

\section{Findings}

\section{Main objectives of the publications}

The publications that solved the problem of hospital selection considered the following main objectives: To design a method for the optimal allocation of patients in ambulances to hospitals $(12,22-28)$; design a system or model for hospital selection decision-making $(10,13,28-30)$; determine the optimal route to the hospital (15,31-35); evaluate or determine the effects of the implementation of mobile applications or information systems over the Internet, for hospital selection (36-39); develop mobile applications or information systems through the Internet for communications, patient transport, and hospital selection $(32,33,40,41)$.

The objectives considered one or several strategic, tactical, and operational decisions of the EMS system. The following are the ones that considered a single decision, such as the selection of the hospital or vehicles routing to the hospital, and those that make multiple decisions of different nature, such as hospital selection with location, dispatch or routing of ambulances.

Hospital selection. Policies for assigning patients transported by ambulance to the emergency rooms of the regional hospital network were defined $(22,26)$. The impact of several hospital selection policies (closer, deviation, join the shorter queue and shorter transfer time) on response time were investigated and the PCC policy was proposed, which integrates three decision principles (Proximity, Congestion, and Centrality) (13). Appropriate diversion policies parameters were found for each hospital in a geographical area, by combining two destination policies with three ambulance diversion policies (42). A hospital selection policy is proposed 
that includes patient and hospital criteria, with the aim of improving pre-hospital care times, the results of which improve the policy of closeness and partial data from historical records of the Bogotá emergency medical care service in 2014 (10).

The effectiveness of the different mechanisms to provide information on the status of hospitals to the EMS and ambulance patients, to decide which hospital will be in better conditions to provide patient care with minimum waiting times, was studied (30); in (29) a support system for decision-making on the individual selection of hospitals is presented; and in (24) a model was designed and implemented to predict the effect of changes in hospital allocation policies, applied to an EMS, on system performance and patient survival.

Some researchers developed real-time medical information systems, with access by mobile applications or by Internet: the effects of mobile application for hospital selection of patients in emergency were evaluated (36); the potential impact of a mobile information system company to support EMS communications was explored, facilitating patients sending to the appropriate hospital (37); mobile technology was analyzed for processes between ambulances and emergency rooms, which helps in the diagnosis and recommends patient admission to a specialized unit (37); the effect of an information system on the current state of the emergency rooms was determined in the diversion of ambulances. In the prehospital stage the patient is classified in the Triage, allowing the EMS to make the decision to transport him to the appropriate hospital (39).

Routing of vehicles to the hospital. An optimal ambulance routing model was designed from the dispatch site to the ambulance base location (31); the best route (the nearest and the fastest) was determined considering the most recent traffic condition. If there are unexpected factors during the transport, the hospital selection can be changed to a nearby one (35).

Hospital selection - Location and number of ambulances. A joint planning model was proposed, which integrates the strategic decision on location and size of the ambulance fleet, and operational decisions on patient allocation in hospitals (23).

Selection of the hospital - vehicle routing. A decision-making system for the selection of an optimal route and a target hospital was designed, considering dynamic factors such as traffic flow, population mobility and hospital capacities (15). It was proposed to develop a mobile application to select the appropriate hospital and the optimal route $(32,33)$.

Hospital selection - ambulance dispatch. It is proposed the development of a comprehensive medical emergency system and its communication processes, for the selection of ambulances and hospitals (40). An integrated cloud-based architecture was developed, which provides information for the selection of appropriate ambulances and hospitals (41). A model was suggested for ambulances dispatch and the selection of the appropriate hospital, based on an 
algorithm that relates the number of available resources of each hospital with transport time, considering the priority of the patients' urgency (12).

\section{Criteria for hospital selection and performance measures}

Table 1 shows the hospital selection criteria and performance measures for the publications that solved the problem of hospital selection. Table 2 displays the hospital selection criteria and strategic, tactical, and operational decisions studied in the publications that mention hospital selection criteria, and the publications that identified hospital selection criteria, according to experiences of patients transferred in ambulances.

The criteria that presented the greatest application were: closeness with $83.33 \%$; hospital care capacities with $62.5 \%$, and shortest queue or highest number of free beds in the emergency room with $45.83 \%$. Some publications consider multiple criteria to select the hospital, others analyze each of the criteria separately, comparing results with performance measures. 
Table 1. Hospital selection criteria and performance measures

\begin{tabular}{|c|c|c|c|c|c|c|c|c|c|c|c|c|c|c|c|c|c|c|c|c|c|c|c|c|c|}
\hline \multirow[b]{2}{*}{ Author(s) } & \multicolumn{11}{|c|}{ Criteria for hospital selection } & \multicolumn{14}{|c|}{ Performance measures (Minimize - Maximize) } \\
\hline & 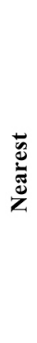 & 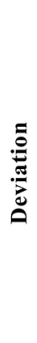 & 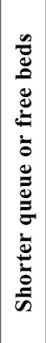 & 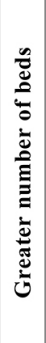 & 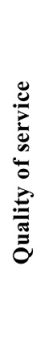 & U. & 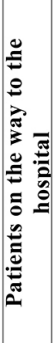 & 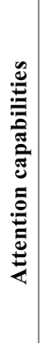 & 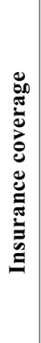 & 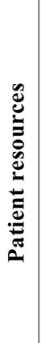 & 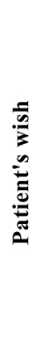 & 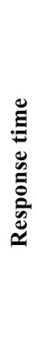 & 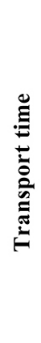 & 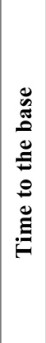 & 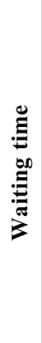 & 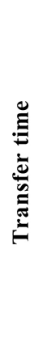 & 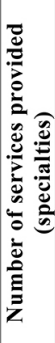 & 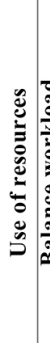 & 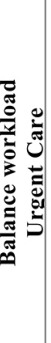 & 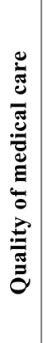 & 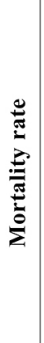 & 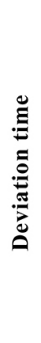 & 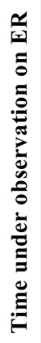 & : & 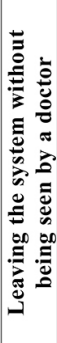 \\
\hline \multicolumn{26}{|l|}{ Urgent care } \\
\hline \multicolumn{26}{|l|}{ (32) Vijayalakshmi et al. (2018) } \\
\hline \multicolumn{26}{|l|}{ (36) Mirino (2017) } \\
\hline \multicolumn{26}{|l|}{ (15) Knyazkov et al. (2015) } \\
\hline \multicolumn{26}{|l|}{ (31) Ramírez-N. et al. (2011) } \\
\hline \multicolumn{26}{|l|}{ (43) Chockalingam et al. (2010) } \\
\hline \multicolumn{26}{|l|}{ (10) Rojas Cortés et al. (2018) } \\
\hline \multicolumn{26}{|l|}{ (26) Almehdawe et al. (2016) } \\
\hline \multicolumn{26}{|l|}{ (22) Leo et al. (2016) } \\
\hline \multicolumn{26}{|l|}{ (23) Yang et al. (2016) } \\
\hline \multicolumn{26}{|l|}{ (13) Lee (2014) } \\
\hline \multicolumn{26}{|l|}{ (12) Gnanasekaran et al. (2013) } \\
\hline \multicolumn{26}{|l|}{ (30) Enders (2010) } \\
\hline \multicolumn{26}{|l|}{ (29) Chi (2009) } \\
\hline \multicolumn{26}{|l|}{ (24) Wears et al. (1993) } \\
\hline \multicolumn{26}{|l|}{ Disaster care } \\
\hline \multicolumn{26}{|l|}{ (25) Sung et al. (2016) } \\
\hline \multicolumn{26}{|l|}{ (27) Bull (2012) } \\
\hline (28) Wang et al. (2012) & & & & & & & & & & & & & & & & & & & & & & & & & \\
\hline (35) Jotshi et al. (2009) & & & & & & & & & & & & & & & & & & & & & & & & & \\
\hline Proposals for the design an & leve & lop & nent & of $i$ & nfor & rma & tion : & and & com & imu & nica & ion & syst & ems & & & & & & & & & & & \\
\hline (37) Katayama et al. (2017) & & & & & & & & & & & & & & & & & & & & & & & & & \\
\hline (34) Nimbalkar et al. (2014) & & & & & & & & & & & & & & & & & & & & & & & & & \\
\hline (33) Househ et al. (2014) & & & & & & & & & & & & & & & & & & & & & & & & & \\
\hline (38) Schooley (2013) & & & & & & & & & & & & & & & & & & & & & & & & & \\
\hline (41) El-Masri et al. (2012) & & & & & & & & & & & & & & & & & & & & & & & & & \\
\hline (42) Poulymenopoulou et al. (2012) & & & & & & & & & & & & & & & & & & & & & & & & & \\
\hline (39) Holtmann (2007) & & & & & & & & & & & & & & & & & & & & & & & & & \\
\hline (40) Sprivulis et al. (2005) & & & & & & & & & & & & & & & & & & & & & & & & & \\
\hline
\end{tabular}

Source: Own elaboration.

In addition to the criteria in table 1, some studies considered other hospital selection policies, such as the preferential selection policy, which considers the historical data of patient transfers to hospitals, to determine a probability of choosing a particular hospital $(30,43,44)$. In the same way, an empirical distribution that characterizes the hospital selection process was determined 
(45-47). Hospitals are assigned within a jurisdiction, which must respond to emergencies presented in this area, considering their proximity to the event $(45,48)$.

Regarding the performance measures in table 1, those that are used most frequently to evaluate the criteria for hospital selection in an individual or integrated manner are: time of transport to the hospital and waiting time in the emergency room, with $33.33 \%$ each; response time, use of resources (ambulances and hospitals or trauma centers) and mortality rate, with $8.33 \%$ each.

Table 2 exhibits the studies focused mostly on the strategic level, with decisions based on location and size of the ambulance fleet with $38.89 \%$ each, and the dispatch of ambulances with $16.67 \%$. Some publications considered the integration of strategic-strategic, strategic-tactical, and strategic-operational decisions. 


\section{Álvaro Junior Caicedo Rolón / Leonardo Rivera Cadavid}

Table 2. Hospital selection criteria and main decision studied

\begin{tabular}{|c|c|c|c|c|c|c|c|c|c|c|c|c|c|c|c|c|c|c|c|c|c|}
\hline \multirow[b]{2}{*}{ Author(s) } & \multicolumn{11}{|c|}{ Criteria for hospital selection } & \multicolumn{10}{|c|}{ Decision studied } \\
\hline & 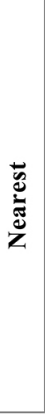 & 总 & 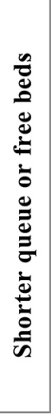 & 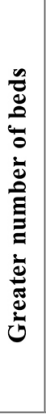 & 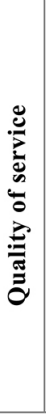 & 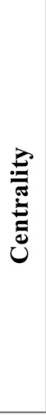 & 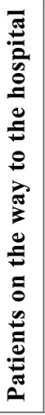 & 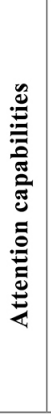 & 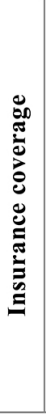 & 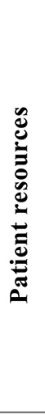 & 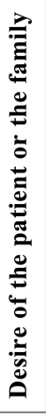 & 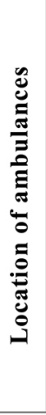 & 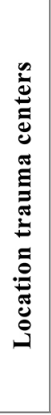 & 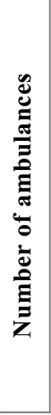 & 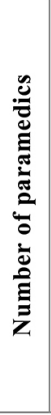 & 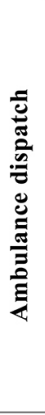 & 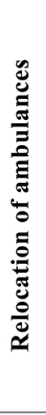 & 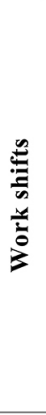 & 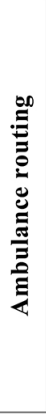 & 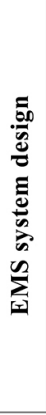 & 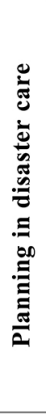 \\
\hline \multicolumn{22}{|l|}{ Urgent care } \\
\hline \multicolumn{22}{|l|}{ (14) Laksono et al. (2017) } \\
\hline \multicolumn{22}{|l|}{ (19) Phyo et al. (2017) } \\
\hline \multicolumn{22}{|l|}{ (11) Aboueljinane (2014) } \\
\hline \multicolumn{22}{|l|}{ (44) Stein (2014) } \\
\hline \multicolumn{22}{|l|}{ (45) Shin et al. (2013) } \\
\hline \multicolumn{22}{|l|}{ (46) Van Buuren et al. (2012) } \\
\hline \multicolumn{22}{|l|}{ (47) Lee et al. (2012) } \\
\hline \multicolumn{22}{|l|}{ (48) Silva et al. (2010) } \\
\hline \multicolumn{22}{|l|}{ (49) Aringhieri et al. (2007) } \\
\hline \multicolumn{22}{|l|}{ (50) Ingolfsson et al. (2003) } \\
\hline \multicolumn{22}{|l|}{ (51) Su et al. (2003) } \\
\hline \multicolumn{22}{|l|}{ (52) Su et al. (2002) } \\
\hline \multicolumn{22}{|l|}{ (53) Repede et al. (1994) } \\
\hline \multicolumn{22}{|l|}{ (54) Swoveland (1973) } \\
\hline \multicolumn{22}{|l|}{ (55) Fitzsimmons (1971) } \\
\hline \multicolumn{22}{|l|}{ (56) Savas (1969) } \\
\hline \multicolumn{22}{|l|}{ Disaster care } \\
\hline \multicolumn{22}{|l|}{ (57) der Heide (2006) } \\
\hline \multicolumn{22}{|l|}{ (58) Inoue (2006) } \\
\hline \multicolumn{22}{|c|}{ Experiences of patients transported in ambulances } \\
\hline (59) Lam et al. (2015) & & & & & & & & & & & & & & & & & & & & & \\
\hline (60) Newgard et al. (2013) & & & & & & & & & & & & & & & & & & & & & \\
\hline (61) Newgard et al. (2011) & & & & & & & & & & & & & & & & & & & & & \\
\hline (62) Vandeventer et al. (2011) & & & & & & & & & & & & & & & & & & & & & \\
\hline (63) Rau et al. (2011) & & & & & & & & & & & & & & & & & & & & & \\
\hline
\end{tabular}

Source: Own elaboration. 


\section{Quantitative methodologies and software}

Table 3 presents the quantitative methodologies applied to the problem of hospital selection, which was classified into mathematical programming, simulation, heuristic and metaheuristic methods.

Table 3. Quantitative methodologies applied in hospital selection research

\begin{tabular}{|c|c|c|c|c|}
\hline \multicolumn{2}{|c|}{ Quantitative methodology } & Reference & $\%$ & $\%$ Total \\
\hline \multirow{10}{*}{$\begin{array}{l}\text { Mathematical } \\
\text { programming }\end{array}$} & Linear programming & {$[27]$} & 3,85 & \multirow{10}{*}{65,38} \\
\hline & $\begin{array}{l}\text { Mixed integer linear } \\
\text { programming }\end{array}$ & {$[22,23,25]$} & 11,54 & \\
\hline & $\begin{array}{l}\text { Linear multiobjective } \\
\text { programming }\end{array}$ & {$[32]$} & 3,85 & \\
\hline & Non-linear programming & {$[26,29]$} & 7,69 & \\
\hline & $\begin{array}{l}\text { Algorithm for the hyper } \\
\text { diminished road }\end{array}$ & {$[32]$} & 3,85 & \\
\hline & Dijkstra Algorithm & {$[32,35,36]$} & 11,54 & \\
\hline & Floyd-Warshall Algorithm & {$[36]$} & 3,85 & \\
\hline & $\begin{array}{l}\text { Queue model } \\
\text { (simple, multiple) }\end{array}$ & {$[13,26]$} & 7,69 & \\
\hline & $\begin{array}{l}\text { Queue model with Markov } \\
\text { Chain }\end{array}$ & {$[26,30]$} & 7,69 & \\
\hline & $\begin{array}{l}\text { Machine learning } \\
\text { (support vector machine) }\end{array}$ & [29] & 3,85 & \\
\hline \multirow{4}{*}{ Simulation } & Discrete events simulation & {$[10,12,13,26,30,31]$} & 23,08 & \multirow{4}{*}{34,62} \\
\hline & Agent-based simulation & {$[28]$} & 3,85 & \\
\hline & $\begin{array}{l}\text { Simulation with Petri } \\
\text { Networks }\end{array}$ & [43] & 3,85 & \\
\hline & \begin{tabular}{|l|} 
Discrete-Continuous \\
Simulation
\end{tabular} & [24] & 3,85 & \\
\hline \multirow{3}{*}{ Heuristic } & $\begin{array}{l}\text { Statistical predictive } \\
\text { algorithm }\end{array}$ & {$[33]$} & 3,85 & \multirow{3}{*}{11,54} \\
\hline & Search algorithm A* & [34] & 3,85 & \\
\hline & $\begin{array}{l}\text { Preparation algorithm } \\
\text { (modified) }\end{array}$ & [12] & 3,85 & \\
\hline Metaheuristics & Genetic algorithm & [31] & 3,85 & 3,85 \\
\hline
\end{tabular}

Source: Own elaboration.

In table 4, the software used to solve mathematical, simulation, heuristic and metaheuristic models were identified. Although a great variety of computer tools were used for the simulation, the Arena software stands out more frequently. The optimization models were mostly solved by 
IBM ILOG CPLEX software. Below is a description of the quantitative methods and software applied, in each of the publications, which are grouped by hospital selection criteria in an individual or integrated manner.

Table 4. Software used

\begin{tabular}{|c|c|c|c|c|}
\hline \multicolumn{2}{|r|}{ Software } & References & $\%$ & \% Total \\
\hline \multirow{3}{*}{ Optimization } & IBM ILOG CPLEX & {$[22,23,25]$} & 15,38 & \multirow{3}{*}{23,08} \\
\hline & Matlab & {$[26]$} & 3,85 & \\
\hline & AIMMS & {$[27]$} & 3,85 & \\
\hline \multirow{13}{*}{ Simulation } & Arena & {$[11,13,30,48]$} & 15,38 & \multirow{13}{*}{92,31} \\
\hline & $\begin{array}{l}\mathrm{C}++ \text { programming } \\
\text { language }\end{array}$ & {$[31,46,47]$} & 11,54 & \\
\hline & SIMSCRIPT II.5 & {$[24,53,55]$} & 11,54 & \\
\hline & eM-Plant & {$[51,52]$} & 7,69 & \\
\hline & $\begin{array}{l}\text { Visual Basic for } \\
\text { Applications }\end{array}$ & {$[10,50,58]$} & 7,69 & \\
\hline & Simio & {$[44]$} & 3,85 & \\
\hline & Simulation AutoMod & {$[41]$} & 3,85 & \\
\hline & $\begin{array}{l}\text { Development of the } \\
\text { US Defense Ministry }\end{array}$ & {$[35]$} & 3,85 & \\
\hline & Microsoft Excel & {$[50]$} & 3,85 & \\
\hline & Promodel & {$[50]$} & 3,85 & \\
\hline & FORTRAN - GPSS & {$[54]$} & 3,85 & \\
\hline & Repast Platform & {$[28]$} & 3,85 & \\
\hline & Anylogic & [49] & 3,85 & \\
\hline \multirow{2}{*}{ Statistics } & BestFit & {$[51,52]$} & 7,69 & \multirow{2}{*}{11,54} \\
\hline & IBM SPSS & {$[70]$} & 3,85 & \\
\hline
\end{tabular}

Source: Own elaboration.

Selection of the hospital with the closest criterion. A mathematical model of optimal routing was designed, which integrates the diffuse multi-objective linear programming and an algorithm for the hyper-diminished path in the proposed EMS system, which minimizes considered times (response + transport to hospital + transport to the base) (31). The best route was determined 
using the Dijkstra algorithm to establish the fastest travel time, and then calculating the fastest distance based on the last traffic condition by applying the Floyd-Warshall algorithm (35). The Dijkstra algorithm was considered with dynamic factors such as traffic flow, road graph change and population mobility (15).

Selection of the hospital with the ambulance diversion criterion. A mathematical model of the flow of patients and resources in a hospital system was developed by means of Petri Nets, which were simulated in the Automod software. A stochastic differential equation that models the proximity of hospitals to enter a state of ambulance diversion to the nearest available hospital was obtained. The utilities and the number of patients leaving the system due to the long waiting times in the emergency room were considered as metrics (49).

Selection of the hospital with the integration of multiple criteria. Studies found the optimal thresholds that define the state of "diversion of ambulances", through multi-objective genetic algorithms and a simulation model to evaluate the performance of the set of integrated criteria (nearest hospital-diversion of ambulances, hospital less congested- diversion of ambulances), for each hospital. The $\mathrm{C}++$ programming language was used in order to minimize transport, waiting, and observation times in the emergency room (42).

Patients in ambulances were assigned to emergency rooms by means of a Mixed Integer Linear Programming (MILP) model that minimizes transportation and waiting time, the penalty of workload imbalance between emergency rooms, and maximizes quality of the care services provided. The model was proposed with relaxation (22). For its part, the MILP model (23) assigns ambulances from location $j$, to meet a demand in district $i$ and transfers it to hospital $h$, considering the level of severity of patients, with the objective of minimizing construction costs of ambulance fleet location, as well as the cost of response and transport times. The theory of the loss of quality of Taguchi was used, which obtained a concave quadratic function that represents the cost of loss of life of patients, in relation to time. The CPLEX software was used to solve the models.

The research of (26) developed: A stylized queueing network model with blocking following a decomposition approach, which was validated through a discrete event simulation (DES) study; a queueing model with Markov chains for a single network of emergency departments, solving their exact distribution in steady state; and an optimization model for finding the probabilities of routing ambulances to emergency rooms, minimizing offload delays, which was solved using Matlab software. In (13) the impact of several hospital selection policies was investigated, which were evaluated in several scenarios through a DES model implemented in the Arena software, minimizing the response, transport, and waiting times. The emergency room was simulated on a single-queue model. (10) The proposed hospital selection policy was evaluated through the DES (Monte Carlo simulation) that was performed in Excel Visual Basic.

A coordination mechanism (hospital selection criteria) or deviation levels was investigated using a simplified queue model, and then a wider variety of coordination mechanisms was considered, 
using a DES model implemented in the Arena software, which minimizes waiting time in the emergency room and maximizes hospital utilities (30). Machine learning methods such as support vector machines were used. These methods learn a decision function that becomes an objective function, and then a multi-objective model that combines lower mortality rate, absence of complications and shorter travel distance was used (29).

The research by (12) modified the preparation algorithm to incorporate ambulance capacity and patient's priority. An algorithm that assigns more priority to the relationship between the available resources of each hospital and the time of transport was proposed. DES was used to simulate different scenarios. In (24), a discrete-continuous simulation model was designed and implemented through the SIMSCRIPT II.5 software, where they experimented with different hospital allocation policies, considering the emergency severity and metrics such as the use of resources (trauma centers and ambulances) and the mortality rate.

For the development of mobile applications: In (32) it is proposed to use a statistical algorithm that will use three data sources to predict the optimal hospital for patients, according to their medical condition, quality ratings of care, waiting times, and shorter distance; in (33) the application will provide the optimal route for the hospital by means of the A* search algorithm.

\section{Technological information and communication}

Table 5 shows the ICT applied in the publications, which are grouped by individual or integrated hospital selection policies, which are presented below. 
Table 5. Information and communication technologies applied

\begin{tabular}{|l|c|c|}
\hline \multicolumn{1}{|c|}{$\begin{array}{c}\text { Information and communication } \\
\text { technologies }\end{array}$} & References & \% \\
\hline Mobile apps & {$[33,34,37,38,41]$} & 33,33 \\
\hline GPS & {$[19,33,34,38,41]$} & 27,78 \\
\hline ArcGis & {$[23,44,47]$} & 16,67 \\
\hline Google Maps & {$[10,29,34,36]$} & 22,22 \\
\hline OpenStreetMap & {$[15]$} & 5,56 \\
\hline Yandex Maps & {$[15]$} & 5,56 \\
\hline MapQuest & {$[29]$} & 5,56 \\
\hline Baidu Maps & {$[23]$} & 5,56 \\
\hline Google earth & {$[19]$} & 5,56 \\
\hline Tele Atlas & {$[46]$} & 5,56 \\
\hline GIS & {$[28,49]$} & 11,11 \\
\hline $\begin{array}{l}\text { Information system of the emergency } \\
\text { room online }\end{array}$ & {$[39-41]$} & 16,67 \\
\hline Electronic health record online & {$[34,41]$} & 11,11 \\
\hline Android operating system Google & {$[34,42]$} & 11,11 \\
\hline Amazon cloud infrastructure & {$[42]$} & 5,56 \\
\hline Apache application server & {$[42]$} & 5,56 \\
\hline $\begin{array}{l}\text { Bluetooth Mobile communication } \\
\text { GSM / HSCSD, GPRS / UMTS }\end{array}$ & {$[39]$} & 5,56 \\
\hline
\end{tabular}

Source: Own elaboration.

Selection of the hospital with the closest criterion. A mobile application with three interfaces is proposed. The startup interface provides an accurate picture of the location to users. The second is the address interface, which shows in order the location of the nearest hospitals as well as the distance and travel time, the hospital image, the address, and the contact number. And the third is the localization interface, which displays the route for the selected hospital (35).

Data sources such as road charts were used from OpenStreetMap and for optimal routes, according to current traffic conditions, Yandex.Maps was used (15). In (50) Tele Atlas data was used for information on road networks and geographic information. The locations of the emergency services (fire, police, and hospitals) were obtained from the Fire Department, Google 
Earth, and the GARMIN etrex-10 GPS device (19). The distance to the place of the scene was calculated using the geographic information system (GIS) (51).

Selection of the hospital with the integration of multiple criteria. In (23) a tool was developed that uses the Baidu Maps JavaScript API functionality, to locate the demand and service nodes directly with the interface, and then accurately obtain the patients in each district. In addition, ArcGIS Map to shows the optimal location of ambulances was used, when several sites are available. In (52) information on the location of candidate sites for trauma centers and heliport bases has been coded geographically to generate their coordinates using the ArcGIS commercial software.

In (45) the incident grouping was done by first drawing all incident coordinates as points on a map, using ArcGIS. Then, a grid overlay was created to cover the extent of the plotted points, using the ArcGIS network tool. Finally, the map layer containing incident points was joined to the grid, and a count of points was made per cell of the grid. In (28), GIS data were used to build a transportation network, along with data on ambulances and hospitals locations, and ambulances available capacity, EMS personnel, and hospital beds. To estimate road distance, (52) proposes to use MapQuest program or Google Maps, (10) used Google Maps API to estimate ambulance travel time.

The following publications are evaluations of mobile applications or information systems in real time, such as:

The ORION application of (36) allows choosing the symptoms listed according to the patient's vital signs and medical background, and then the appropriate hospitals are listed with their availability, and a telephone call is automatically made to the chosen hospital to confirm acceptation. The application of (37) allows to capture and transmit digital images, video and digital audio, about patients and information related to emergency incidents to the appropriate hospital before arrival, as well as the location, using global positioning system (GPS).

The application of (41) allows the selection of appropriate ambulances and hospitals, based on patient triage, availability of hospital resources, proximity and, optionally, the load balance. Amazon's cloud infrastructure was used for the prototype. The workflow module, the REST services, and the developed web application were hosted on the Apache application server, while the mobile application was developed on Google's Android operating system.

The Stroke Angel system of (38) helps in the diagnosis of cerebrovascular accidents and manage of other patient data, where the system issues a stroke alert and recommends the patient's admission to a specialized unit. The information is sent to the emergency room so that it is prepared. The system is connected via Bluetooth to a mobile phone, which establishes a wireless data link using mobile communication technologies such as GSM / HSCSD, GPRS or UMTS. 
An information system, accessible via the internet, was proposed in real time, which provides data on the current status of the emergency departments, regarding workload conditions (http:/ /www.health.wa.gov.au/emergencyactivity/edsv/index.cfm) (40).

The following publications propose designs for mobile applications, such as:

The application of (33) will allow access to the electronic medical record of the patient, use the database to find the nearest specialized hospital available and suggest a list to the user, depending on the type of emergency, doctor availability, and distance from the patient. In addition, it will provide the optimal route and current hospital data, such as available beds and the number of physicians available with their respective specialization. The application will use Google Maps, GPS, and Google's Android mobile operating system.

The application of (32) will provide patients with an interface to choose the optimal emergency room with the shortest travel time and the shortest route (using Google Maps and GPS), the shortest waiting times and the best quality of attention. The system proposed by (40) will allow locating the nearest ambulance, creating a record of the patient's medical condition that will be communicated to the hospital, and this will be linked to their electronic medical record, then the application selects the nearest specialized hospital, presenting information on the availability of beds and resources. It will be necessary that mobile phones and ambulances are equipped with GPS.

\section{Discussion}

The objectives defined in the publications propose one or several decisions at a strategic, tactical and operational level of the EMS system. The selection of the hospital has been oriented towards the design of models or the assignment of patients in ambulances to emergency rooms, with little implementation. The hospital selection has been integrated with the location, dispatch, routing or size of the ambulance fleet. In (7) the programming approach was identified at two levels, including location decisions and routing strategies, such as problems incorporated within one another.

The study reveals that the most frequent criteria for hospital selection were closeness, hospital care capacity and a shorter queue or greater number of free beds in the emergency room. In Pittsburgh (USA) (30), about $90 \%$ of patients have an emergency room preference based on their health insurance or the location of their home. However, in Edmonton (Canada), more than 50\% of patients are not transported to the nearest hospital $(44)$. In $(53,54)$ it was identified that the desire of the family or of the patient victim of trauma are the most common reasons for selecting hospitals. In (55) the selection criterion is the hospital's capacity for care, but there were patients with mild severity who were transported to a high-level hospital, without considering a longer waiting period, contributing to the over-occupation of the emergency rooms. In (9) the results of the simulation showed that the combination of decision criteria worked better than decisions based on few or no criteria (random assignment) with respect to the measure of mortality. 
According to the hospital selection criteria identified, it can be analyzed that closeness does not always have good results in the case of non-critical patients, since emergency rooms may have long waiting times. In the case of the criterion of the shorter queue or free beds (congestion), not all EMS systems have this information in real time, since some lack information and communication technologies. Hospital care capabilities are not always well used, since highlevel hospital mostly care for patients with mild or moderate medical conditions. And insurance coverage restricts access to certain hospitals that might be good candidates. Because of this, the EMS system could be affected in the following way: overcrowding in the emergency rooms, in the time slots and days of the week of greater demand; long delivery times of the patient in the emergency room; delays in the return of stretchers, leaving the ambulances out of service; and diversion of the ambulances to other medical centers, which puts the health of the patient at risk and affects the efficiency of the EMS system.

The most used performance measures were the shortest transport and waiting time in the emergency room. In (4) there are few EMS planning studies at the operational level related to the transport of patients. Hence the importance of investigating the improvement of transport times, to provide solutions to real problems, considering (7) the dynamic and complex nature of the EMS systems and the variability of transport times.

In general terms, the research that aims to solve the problem of hospital selection by quantitative methods only reaches the design phase. Few cases show the implementation and permanent use of the tools designed, such as the study (22) whose methodology and developed software are currently used by the Department of Epidemiology of Lazio, Italy. Research on mobile applications or information systems over the internet has been focused on the design and implementation process; however, in (32) there was difficulty in the design and availability of information in time real, making modifications to the initial approach.

The majority of researchers considered the design of optimization models, using exact methods such as linear programming, MILP, nonlinear programming and single or multiple queue models, which were validated by DES models. In order to determine the best route to reach the scene and then to reach the hospital, the traditional, dynamic and modified Dijkstra algorithm was used. Some publications also consider current traffic conditions. There is little application of metaheuristics in the problem of hospital selection. The optimization models and the simulation models were mostly solved through the CPLEX and Arena software, and the $\mathrm{C}++$ programming language, respectively.

In (16) and in (56) DES and mathematical programming were also identified as the main quantitative methodologies, for the problems of the relocation of vehicles of EMS and the optimization of the emergency rooms, respectively. In (57) the queuing theory was identified to solve the problem of overcrowding in emergency rooms. For (9) simulation, mathematical programming, and queuing theory models have been used to improve the performance of EMSs. 
Most of the simulation studies focused on the location decision, and the mathematical models for the relocation problem. In (6) most simulation approaches are based on DES. Despite the availability of many mathematical tools and information technologies that support decisionmaking, in Italy, the EMSs usually locate and manage their ambulances based on the experience of the operators and not on quantitative tools (58).

For (6) further research is required in optimization hybrids with other quantitative methodologies, to understand when the simulation should be preferred to analytical models. The combination of optimization techniques with stochastic (generalized) Petri Nets, which can be solved more efficiently than a DES model, seems unexplored. Due to the nature of uncertainty in the EMS system, (7) they state that robust optimization models are useful to consider the worst scenarios, providing valuable insight for decision making.

In the literature reviewed, some mobile applications have been developed or planned to be developed in Google's Android operating system. To determine a specific location, information on the road network and the shortest route, the researchers used or plan to use a wide variety of GIS software, most often ArcGIS and Google Maps, along with the requirement that ambulances and mobile devices have a GPS. In (9) GPS in ambulances, to determine geographical position, and GIS, to model travel times, are useful to evaluate more realistic contexts and to measure the impact of periodic updating of the positions of rescue teams throughout the day, in terms of costs and punctuality. The importance of the use of GPS and GIS are highlighted, which have allowed obtaining and processing data in real time, necessary to work on the problem of vehicle relocation (16). In (6) to manage over-occupation, a pilot project on the use of ICT that provide real-time data on the workload is underway in Italy.

The development and implementation of ICT, using mobile applications and internet information systems, require an investment in the EMS system for its operation and functioning, such as equipment, software, devices, and personnel, which guarantee the transmission of information and communication in real-time, between the actors of the system. As countries develop in science and technology, and as a political class committed to health includes this type of technical and technological development in its budget, the probability that developing countries will adopt these technologies and improve the delivery of services in the EMS system increases.

The reality of some EMS systems is that they make decisions subjectively, based on experience as presented in Italy (58) and in Bogotá, Colombia, where the selection of the hospital is made by the regulating physician, from the emergency regulation center, without any support from a quantitative tool (10). Another aspect is that emergency rooms are generally overcrowded, so selecting the appropriate hospital is very important (13), to maintain a balanced workload in the emergency network, applicable in countries with a universal health care system, such as Australia and Canada (29), and ensure timely care for patients. Therefore, this literature review presents a variety of applied methodologies for government, health authorities and EMS managers to conduct research and implement appropriate information and communication 
methods and technologies, with scientific support from universities and specialized research centers through the establishment of agreements to contribute improve the management and operation of the EMS system.

\section{Conclusions}

There is a widespread concern among researchers to improve the performance of EMS systems in developed countries in North America, Asia and Europe, where the largest number of studies is evident. Publications show that the hospital selection has been integrated with other decisions such as location, dispatch, routing and size of the ambulance fleet. Among the hospital selection criteria and the performance measures considered in the EMS system are proximity, hospital care capacity, the shortest queue or the largest number of free beds, and the shortest transport time and wait in the emergency room, respectively. The application of the DES and the mathematical programming methods that were solved through the software CPLEX, Arena, and the programming language $\mathrm{C}++$ were identified. The application of metaheuristics in the problem of hospital selection is scarce.

Due to technological advances in information and communication systems, mobile applications and Internet information systems have been implemented in developed countries such as the USA, Japan, Germany, and Australia, which provide real-time information on the occupation conditions of the emergency rooms, and allow online data transmission of the patient's medical history, to support decision-making processes at the operational level, such as hospital selection.

It is recommended that investigations continue to be carried out in the hospital selection decision since it is one of the least studied in the literature of the EMS system. This decision should be integrated with others at a strategic, tactical and operational level considering the integration of selection criteria that include health insurance coverage (it depends on the health system of each country), the quality of service and the patient's desire. Likewise, it is recommended that they are evaluated by means of DES models such as Petri Nets, due to the complex and stochastic nature of the system, adopting the appropriate performance measures for the improvement of the EMS system. Finally, it is recommended that the design of hospital selection methods be implemented as well as the technological developments, considering the participation of the actors of the EMS system.

\section{Ethical considerations}

The authors declare that this article is original, and they are responsible for its contents. 


\section{References}

1. Ministerio de Salud y Protección Social. Resolución 0926 del 30 de marzo de 2017. Por la cual se reglamenta el desarrollo y operación del Sistema de Emergencias Médicas. Bogotá; 2017.

2. Congreso de la Republica de Colombia. Ley 1438 del 19 enero de 2011. Bogotá; 2011.

3. Holtermann KA, Ross AG. Desarrollo de sistemas de servicios de emergencias médicas: experiencia de los Estados Unidos de América para países en desarrollo. Washington DC: PAHO; 2003.

4. Reuter-Oppermann M, van den Berg PL, Vile JL. Logistics for emergency medical service systems. Health Systems. 2017;6(3):187-208. https://doi.org/10.1057/s41306-017-0023-X

5. Barroeta J, Boada N. Los servicios de emergencia y urgencias médicas extra-hospitalarias en España. Madrid: Mensor; 2011.

6. Aringhieri R, Bruni ME, Khodaparasti S, Van Essen JT. Emergency medical services and beyond: Addressing new challenges through a wide literature review. Computers \& Operations Research. 2017;78:349-368. https://doi.org/10.1016/j.cor.2016.09.016

7. Gholami-Zanjani S, Pishvaee M, Torab S. OR Models for Emergency Medical Service (EMS) Management. In: Kahraman C, et al. (eds). Operations Research Applications in Health Care Management. Springer; 2018. p.395-422.

8. Kergosien Y, Bélanger V, Soriano P, Gendreau M, Ruiz A. A generic and flexible simulation-based analysis tool for EMS management. Int J Prod Res. 2015;53(24):7299-7316. https://doi.org/10.108 0/00207543.2015.1037405

9. Aboueljinane L, Sahin E, Jemai Z. A review on simulation models applied to emergency medical service operations. Comput Ind Eng. 2013;66(4):734-750. https://doi.org/10.1016/j.cie.2013.09.017

10. Rojas Cortés V, Romero L, Barrera D, Suárez DR. Selección de hospital destino para el traslado de urgencia de pacientes. Rev Gerenc Polit Salud. 2018;17(35):1-17. https://doi.org/10.11144/Javerian a.rgps 17-35.shdt

11. Aboueljinane L, Sahin E, Jemai Z, Marty J. A simulation study to improve the performance of an emergency medical service: Application to the French Val-de-Marne department. Simulation modelling practice and theory. 2014;47:46-59. https://doi.org/10.1016/j.simpat.2014.05.007

12. Gnanasekaran AM, Moshref-Javadi M, Zhong H, Moghaddam M, Lee S. Impact of patient's priority and resource availability in ambulance dispatching. In IIE Annual Conference. Proceedings. Institute of Industrial and Systems Engineers (IISE); 2013.

13. Lee S. The role of hospital selection in ambulance logistics. IIE Transactions on Healthcare Systems Engineering. 2014;4(2):105-117. https://doi.org/10.1080/19488300.2014.914608

14. Laksono P, Wulan SR, Supangkat SH, Sunindyo WD. AHP and dynamic shortest path algorithm to improve optimum ambulance dispatch in emergency medical response. In ICT For Smart Society (ICISS), 2017 International Conference on. IEEE; 2017. p.1-6.

15. Knyazkov K, Derevitsky I, Mednikov L, Yakovlev A. Evaluation of dynamic ambulance routing for the transportation of patients with acute coronary syndrome in Saint-Petersburg. Procedia Computer Science. 2015;66:419-428. https://doi.org/10.1016/j.procs.2015.11.048 
16. Rodríguez AK, Osorno GM, Maya PA. Relocalización de vehículos en servicios de emergencias médicas: una revisión. Ingeniería y Ciencia. 2016;12(23):163-202. https://doi.org/10.17230/ingcien cia.12.23.9

17. López M, Vinicio H. Modelo cuantitativo para la localización de ambulancias de gestión sanitaria y su impacto en los tiempos de arribo, coordinadas por el Centro Local ECU911 Macas dentro de la provincia de Morona Santiago. Tesis de maestría. Ambato: Universidad Técnica de Ambato; 2017.

18. Tlili T, Harzi M, Krichen S. Swarm-based approach for solving the ambulance routing problem. In International Knowledge Based and Intelligent Information and Engineering Systems, KES2017, 6-8 September. Marseille: Procedia Computer Science; 2017. p.350-357.

19. Phyo KZ, Sein MM. Optimal Route Assessment for Emergency Vehicles Travelling on Complex Road Network. In: International Workshop on Multi-disciplinary Trends in Artificial Intelligence. Cham: Springer; 2017. p.380-390.

20. Azizan M, Lim C, Hatta W, Go L, Teoh S. Simulation of emergency medical services delivery performance based on real map. Int J Eng Technol. 2013;5(3):2620-2627. http://citeseerx.ist.psu.ed $\mathrm{u} / \mathrm{viewdoc} /$ download?doi=10.1.1.411.2313\&rep=rep1\&type $=$ pdf

21. Fernández-Altuna M, Martínez del Prado A, Arriarán Rodríguez E, Gutiérrez Rayón D, Toriz Castillo, H \& Lifshitz Guinzberg A. Uso de los MeSH: una guía práctica. Investigación en educación médica. 2016;5(20):220-229. https://doi.org/10.1016/j.riem.2016.02.004

22. Leo G, Lodi A, Tubertini P, Di Martino M. Emergency department management in Lazio, Italy. Omega. 2016;58:128-138. https://doi.org/10.1016/j.omega.2015.05.007

23. Yang D, Liu M, Su Q. Cost-effective analyses of joint planning in emergency medical services: A case study. In Service Systems and Service Management (ICSSSM), 2016 13th International Conference on. IEEE; 2016. p.1-6.

24. Wears RL, Winton CN. Simulation modeling of prehospital trauma care. In Simulation Conference Proceedings, 1993. Winter. IEEE; 1993. p.1216-1224.

25. Sung I, Lee T. Optimal allocation of emergency medical resources in a mass casualty incident: Patient prioritization by column generation. Eur J Oper Res. 2016;252(2):623-634. https://doi.org/10.1016 /j.ejor.2016.01.028

26. Almehdawe E, Jewkes B, He QM. Analysis and optimization of an ambulance offload delay and allocation problem. Omega. 2016;65:148-158.

27. Bull M. An Index to Measure Efficiency Of Hospital Networks for Mass Casualty Disasters. Doctoral dissertation. University of Central Florida; 2012.

28. Wang Y, Luangkesorn KL, Shuman L. Modeling emergency medical response to a mass casualty incident using agent-based simulation. Socio-Economic planning sciences. 2012;46(4):281-290. https://doi.o $\mathrm{rg} / 10.1016 /$ j.seps.2012.07.002

29. Chi CL. Medical decision support systems based on machine learning. Doctoral dissertation. University of Iowa; 2009. 
30. Enders P. Applications of stochastic and queueing models to operational decision making. Doctoral dissertation. Carnegie Mellon University; 2010.

31. Vijayalakshmi C, Anitha N. Design of an Optimization Routing Model for Real Time Emergency Medical Service System in Chennai Using Fuzzy Techniques. Jude D, Smys S (eds). Computational Vision and Bio Inspired Computing. Cham: Springer; 2018. p.266-279.

32. Househ MS, Yunus F. Emergency Department Waiting Times (EDWaT): A patient flow management and quality of care rating mHealth application. In ICIMTH; 2014. p.229-232.

33. Nimbalkar RA, Fadnavis RA. Domain specific search of nearest hospital and Healthcare Management System. In Engineering and Computational Sciences (RAECS), 2014 Recent Advances in. IEEE; 2014. p.1-5.

34. Jotshi A, Gong Q, Batta R. Dispatching and routing of emergency vehicles in disaster mitigation using data fusion. Socio-Econ Plan Sci. 2009;43(1):1-24. https://doi.org/10.1016/j.seps.2008.02.005

35. Mirino AE, Risald, Suyoto. Best routes selection using Dijkstra and Floyd-Warshall algorithm. In Information \& Communication Technology and System (ICTS), 2017 11th International Conference on. IEEE; 2017. p.155-158.

36. Katayama Y, Kitamura T, Kiyohara K, Iwami T, Kawamura T, Izawa, J, et al. Improvements in patient acceptance by hospitals following the introduction of a smartphone app for the emergency medical service system: A population-based before-and-after observational study in Osaka City, Japan. JMIR mHealth and uHealth; 2017;5(9). https://doi.org/10.2196/mhealth.8296

37. Schooley BL, Murad A, Abed Y, Horan TA. A mHealth system for patient handover in emergency medical services. In ISCRAM; 2013.

38. Holtmann C, Müller-Gorchs M, Rashid A, Weidenhaupt K, Ziegler V, et al. Medical opportunities by mobile IT usage-a case study in the stroke chain of survival. In: European Conference on eHealth 2007; 2007.

39. Sprivulis P, Gerrard B. Internet-accessible emergency department workload information reduces ambulance diversion. Prehosp Emerg Care. 2005;9(3):285-291. https://doi.org/10.1080/109031205 90962094

40. El-Masri S, Saddik B. An emergency system to improve ambulance dispatching, ambulance diversion and clinical handover communication. A proposed model. J Med Syst. 2012;36(6):3917-3923. http s://doi.org/10.1007/s10916-012-9863-x

41. Poulymenopoulou M, Malamateniou F, Vassilacopoulos G. Emergency healthcare process automation using mobile computing and cloud services. J Med Syst. 2012;36(5):3233-3241. https://doi.org/10. 1007/s10916-011-9814-y

42. Ramírez-Nafarrate A, Fowler JW, Wu T. Design of centralized ambulance diversion policies using simulation-optimization. In Proceedings of the Winter Simulation Conference. Winter Simulation Conference; 2011. p.1251-1262.

43. Shin K, Sung I, Lee T. Emergency medical service system design evaluator. In Proceedings of the 2013 Winter Simulation Conference: Simulation: Making Decisions in a Complex World. IEEE Press; 2013. p.2410-2421. 
44. Ingolfsson A, Erkut E, Budge S. Simulation of single start station for Edmonton EMS. J Oper Res Soc. 2003;54(7):736-746. https://doi.org/10.1057/palgrave.jors.2601574

45. Stein OA. Emergency medical service response system performance in an urban South African setting: a computer simulation model. Doctoral dissertation. University of Cape Town; 2014.

46. $\mathrm{Su} \mathrm{S}$, Shih $\mathrm{CL}$. Resource reallocation in an emergency medical service system using computer simulation. The American journal of emergency medicine. 2002;20(7):627-634. https://doi.org/10.1 053/ajem.2002.35453

47. Repede JF, Bernardo JJ. Developing and validating a decision support system for locating emergency medical vehicles in Louisville, Kentucky. Eur J Oper Res. 1994;75(3):567-581. https://doi.org/10.1 016/0377-2217(94)90297-6

48. Su S, Shih CL. Modeling an emergency medical services system using computer simulation. Int J Med Inform. 2003;72(1-3):57-72. https://doi.org/10.1016/j.ijmedinf.2003.08.003

49. Chockalingam A, Jayakumar K, Lawley MA. A stochastic control approach to avoiding emergency department overcrowding. In Simulation Conference (WSC), Proceedings of the 2010 Winter. IEEE; 2010. p.2399-2411.

50. Van Buuren M, van der Mei R, Aardal K, Post H. Evaluating dynamic dispatch strategies for emergency medical services: TIFAR simulation tool. In Simulation Conference (WSC), Proceedings of the 2012 Winter. IEEE; 2012.

51. Aringhieri R, Carello G, Morale D. Ambulance location through optimization and simulation: The case of Milano urban area; 2007.

52. Lee T, Cho SH, Jang H, Turner JG. A simulation-based iterative method for a trauma center - Air ambulance location problem. In Simulation Conference (WSC), Proceedings of the 2012 Winter. IEEE; 2012.

53. Newgard CD, Mann NC, Hsia RY, Bulger EM, Ma OJ, Staudenmayer K, et al. Patient choice in the selection of hospitals by $9 \# 1 \# 1$ emergency medical services providers in trauma systems. Acad Emerg Med. 2013;20(9):911-919. https://doi.org/10.1111/acem.12213

54. Newgard, CD, Nelson MJ, Kampp M, Saha S, Zive D, Schmidt T, et al. Out-of-hospital decision-making and factors influencing the regional distribution of injured patients in a trauma system. $\mathrm{J}$ Trauma. 2011;70(6):1345. https://doi.org/10.1097/TA.0b013e3182191a1b

55. Vandeventer S, Studnek JR, Garrett JS, Ward SR, Staley K, Blackwell T. The association between ambulance hospital turnaround times and patient acuity, destination hospital, and time of day. Prehosp Emerg Care. 2011;15(3):366-370. https://doi.org/10.3109/10903127.2011.561412

56. Velásquez-Restrepo PA, Rodríguez-Quintero AK, Jaén-Posada, JS. Metodologías cuantitativas para la optimización del servicio de urgencias: Una revisión de la literatura. Rev Gerenc Polit Salud. 2011;10(21):196-218. https://www.redalyc.org/pdf/545/54522293012.pdf 
57. Hoot NR, Aronsky D. Systematic review of emergency department crowding: Causes, effects, and solutions. Ann Emerg Med. 2008;52(2):126-136. https://doi.org/10.1016/j.annemergmed.2008.03.0 14

58. Aringhieri R, Carello G, Morale D. Supporting decision making to improve the performance of an Italian Emergency Medical Service. Ann Oper Res. 2016;236(1):131-148. https://doi.org/10.1007/s10479013-1487-0 